\title{
Dependence of scar contrast in LGE images on the time interval after contrast injection
}

\author{
Sathya Vijayakumar*, Eugene G Kholmovski, Nassir F Marrouche \\ From 2011 SCMR/Euro CMR Joint Scientific Sessions \\ Nice, France. 3-6 February 2011
}

\begin{abstract}
Aim
To study the dependence of post-ablation scar visibility in late gadolinium enhancement (LGE) images of left arial wall on time interval after contrast agent injection

\section{Introduction}

It was shown that LGE imaging can be used to evaluate post-ablation scar $[1,2]$ and pre-ablation remodeling of left atrium [3]. Visibility of scar depends on a time interval between contrast agent injection and LGE scan. In this study, we try to determine, what time post contrast injection would give optimal contrast between post-ablation scar and blood $\left(\mathrm{CNR}_{\mathrm{SB}}\right)$ and scar and normal myocardium $\left(\mathrm{CNR}_{\mathrm{SM}}\right)$.
\end{abstract}

\section{Methods}

The study was performed retrospectively on 3-month post ablation LGE data acquired on a $3 \mathrm{~T}$ Verio scanner (Siemens Healthcare, Erlangen, Germany) with a full dose $(0.1 \mathrm{mmol} / \mathrm{kg})$ of contrast agent (Multihance, Bracco Diagnostic Inc., Princeton, NJ). The data were separated into 3 groups based on time post contrast:

1) 20-30 mins post contrast

2) 30-40 mins post contrast

3) 40-45 mins post contrast

Each group had 12 patients. Contrast to Noise Ratio (CNR) was computed as the ratio of the difference in signal intensity over a chosen region of interest in the scar and normal myocardium and the standard deviation of the noise observed in the blood pool. CNR was computed between scar and normal myocardium $\mathrm{CNR}_{\mathrm{SM}}$ \& between scar and blood $\mathrm{CRN}_{\mathrm{SB}}$.

\section{Results}

Table 1 shows the results of the analysis. Figure 1 shows a comparative image of the CNR measurement made in 3 datasets, one from each group. Unpaired Student's $\mathrm{t}$-test was performed on these datasets and the $\mathrm{p}$ values were found to be $-\mathrm{p}=0.24$ (for $\mathrm{CNR}_{\mathrm{SB}}$ between $<30 \mathrm{~min}$ and 30-40min); $\mathrm{p}=0.69$ (for $\mathrm{CNR}_{\mathrm{SB}}$ between $30-40 \mathrm{~min}$ and $>40 \mathrm{~min}$ ); $\mathrm{p}=0.97$ (for $\mathrm{CNR}_{\mathrm{SM}}$ between $<30 \mathrm{~min}$ and $30-40 \mathrm{~min}$ ) and $\mathrm{p}=0.54$ (for $\mathrm{CNR}_{\mathrm{SM}}$ between $30-40 \mathrm{~min}$ and $>40 \mathrm{~min}$ ). Thus, the difference in CNR between scar and normal myocardium and scar and blood observed in all three groups is not statistically significant.

\section{Conclusion}

From these preliminary results, it follows that LGE imaging performed between 25 to 45 minutes post contrast injection give comparable visibility of post ablation scar.

Table 1 CNR computed for each studied group

\begin{tabular}{lll}
\hline Time post contrast & $\mathbf{C N R}_{\mathbf{S M}}($ mean $\pm \mathbf{s t d})$ & $\mathbf{C R N}_{\mathbf{S B}}($ mean $\pm \mathbf{s t d})$ \\
\hline $25.2 \pm 4$ minutes & $20.3 \pm 9.1$ & $8.7 \pm 4.8$ \\
$34.3 \pm 2.5$ minutes & $20.2 \pm 8.8$ & $11.3 \pm 5.9$ \\
$42 . \pm 2.8$ minutes & $17.3 \pm 3.5$ & $10 \pm 1.9$ \\
\hline
\end{tabular}




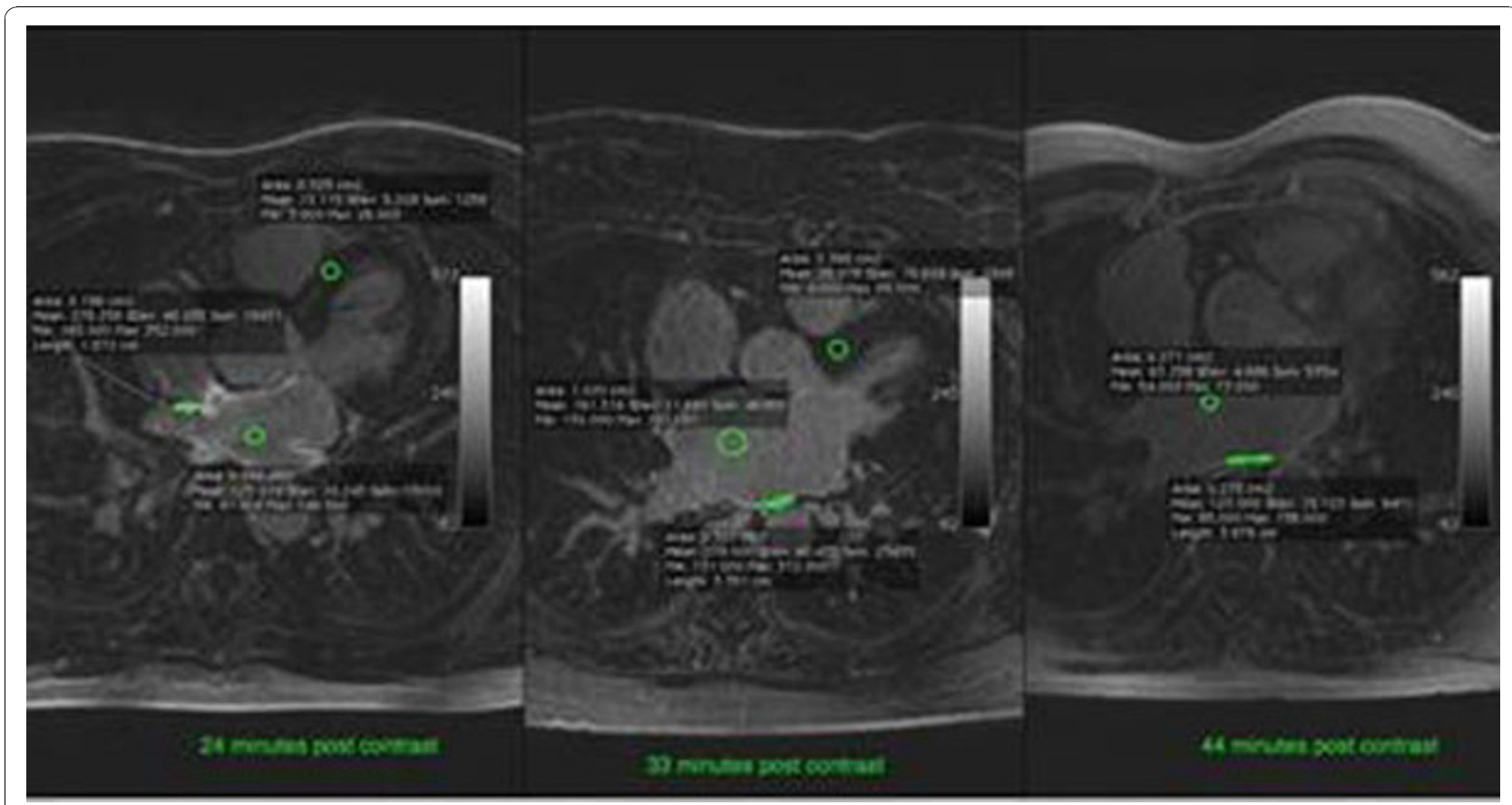

Figure 1 The measurement of CNR in representative images from the studied groups.

Published: 2 February 2011

\section{References}

1. Peters DC, et al: Radiology 2007, 243(3):690-5.

2. McGann CJ, et al: JACC 2008, 52(15):1263-71.

3. Oakes RS, et al: Circulation 2009, 119(13):1758-67.

\section{doi:10.1186/1532-429X-13-S1-P42}

Cite this article as: Vijayakumar et al.: Dependence of scar contrast in

LGE images on the time interval after contrast injection. Journal of

Cardiovascular Magnetic Resonance 2011 13(Suppl 1):P42.

\section{Submit your next manuscript to BioMed Central and take full advantage of:}

- Convenient online submission

- Thorough peer review

- No space constraints or color figure charges

- Immediate publication on acceptance

- Inclusion in PubMed, CAS, Scopus and Google Scholar

- Research which is freely available for redistribution 